\title{
Laparoscopic extraperitoneal rectal cancer surgery: the clinical practice guidelines of the European Association for Endoscopic Surgery (EAES)
}

\author{
R. Siegel $\cdot$ M. A. Cuesta $\cdot$ E. Targarona $\cdot$ F. G. Bader $\cdot$ M. Morino $\cdot$ \\ R. Corcelles · A. M. Lacy $\cdot$ L. Påhlman • E. Haglind $\cdot$ K. Bujko • \\ H. P. Bruch • M. M. Heiss · M. Eikermann · E. A. M. Neugebauer
}

Received: 12 May 2011/Accepted: 24 May 2011/Published online: 24 June 2011

(C) Springer Science+Business Media, LLC 2011

\begin{abstract}
Background The laparoscopic approach is increasingly applied in colorectal surgery. Although laparoscopic surgery in colon cancer has been proved to be safe and feasible with equivalent long-term oncological outcome compared to open surgery, safety and long-term oncological outcome of laparoscopic surgery for rectal cancer remain controversial. Laparoscopic rectal cancer surgery might be efficacious, but indications and limitations are not clearly defined. Therefore, the European Association for Endoscopic Surgery (EAES) has developed this clinical practice guideline.

Methods An international expert panel was invited to appraise the current literature and to develop evidence-based
\end{abstract}

\section{R. Siegel · M. M. Heiss}

Department of Visceral, Vascular, and Transplantation Surgery, Faculty of Health, Witten/Herdecke University, Campus

Cologne-Merheim, Cologne, Germany

M. A. Cuesta

Department of Surgery, VU University Medical Centre,

Amsterdam, The Netherlands

\section{E. Targarona}

Service of Surgery, Hospital de Sant Pau, University

Autonomous of Barcelona, Barcelona, Spain

F. G. Bader · H. P. Bruch

Department of Surgery, University of Schleswig-Holstein,

Campus Lübeck, Lübeck, Germany

\section{Morino}

Digestive Surgery and Center for Minimally Invasive Surgery, Department of Surgery, University of Turin, Turin, Italy

R. Corcelles · A. M. Lacy

Department of Gastrointestinal Surgery, Hospital Clinic,

University of Barcelona, Barcelona, Spain recommendations. The expert panel constituted for a consensus development conference in May 2010. Thereafter, the recommendations were presented at the annual congress of the EAES in Geneva in June 2010 in a plenary session. A second consensus process (Delphi process) of the recommendations with the explanatory text was necessary due to the changes after the consensus conference.

Results Laparoscopic surgery for extraperitoneal (midand low-) rectal cancer is feasible and widely accepted. The laparoscopic approach must offer the same quality of surgical specimen as in open surgery. Short-term outcomes such as bowel function, surgical-site infections, pain and hospital stay are slightly improved with the laparoscopic approach. Laparoscopic resection of rectal cancer is not

\footnotetext{
L. Påhlman

Department of Surgical Science, Akademiska Sjukhuset, University of Uppsala, Uppsala, Sweden

E. Haglind

Department of Surgery, Sahlgrenska University Hospital/Östra, Göteborg, Sweden

K. Bujko

Department of Radiotherapy, Maria Sklodowska-Curie

Memorial Cancer Centre, Warsaw, Poland

M. Eikermann · E. A. M. Neugebauer $(\bowtie)$

Institute for Research in Operative Medicine (IFOM),

Chair for Surgical Research, Faculty of Health,

Witten/Herdecke University, Campus Cologne-Merheim,

Ostmerheimer Straße 200, 51109 Köln, Germany

e-mail: edmund.neugebauer@uni-wh.de
} 
inferior to the open in terms of disease-free survival, overall survival or local recurrence. Laparoscopic pelvic dissection may impair genitourinary and sexual function after rectal resection, like in open surgery.

Conclusions Laparoscopic surgery for mid- and low-rectal cancer can be recommended under optimal conditions. Still, most level 1 evidence is for colon cancer surgery rather than rectal cancer. Upcoming results from large randomised trials are awaited to strengthen the evidence for improved shortterm results and equal long-term results in comparison with the open approach.

Keywords Guidelines - Laparoscopy $\cdot$ Minimally invasive surgery $\cdot$ Rectal cancer

The incidence of fatal cases of colorectal cancer in Europe exceeds 200,000 per year. According to European registries, rectal cancer has prevalence of more than 50 per 100,000 (women and men) and accounts for almost $40 \%$ of all colorectal cancer cases [1,2]. Despite ongoing efforts in screening and improvements in multimodal therapy, colorectal cancer is still one of the leading causes of cancer mortality. Especially local recurrence is a major problem in locally advanced rectal cancer. Surgery remains the mainstay of therapy, with a standardized and quality-controlled technique, i.e. total mesorectal excision (TME). Pioneers have shown feasibility of laparoscopic resection of rectal cancer, leading to a surge of this approach in recent years. Although the laparoscopic approach in colon cancer has been proved to be safe and feasible with equivalent longterm oncological outcome compared to open surgery [3-5], safety of laparoscopic surgery for rectal cancer remains debatable. Laparoscopic resection of rectal cancer might be efficacious, but this, as well as morbidity and oncological outcome, need to be demonstrated. The European Association for Endoscopic Surgery (EAES) therefore perceived the need to hold a consensus development conference (CDC) on laparoscopic extraperitoneal rectal cancer surgery and thence provide clinical practice guidelines.

\section{Methods}

The EAES scientific committee commissioned the planning group in Cologne to take over the organisation of the guideline development and to undertake a systematic literature search.

Selection of topics and experts

An international expert panel was invited to appraise the current literature and to develop evidence-based recommendations. An expert panel constituted for a consensus development conference (CDC) in May 2010 consisted of surgeons, oncologists, radiotherapist and research scientists. Experts were selected according to their scientific and clinical expertise as well as geographical location.

The key topics were formulated, consented and adopted by the guideline development group. For every key topic a coordinator was nominated, being responsible for literature appraisal and evidence synthesis for the assigned topic. Three or four selected subgroup members supported the coordinator.

Literature searches and appraisal

A systematic literature search was conducted in the electronic databases MEDLINE (Pubmed) and Cochrane Library for the years 2000-2010 (for some research questions also from 1990 to 2010) to identify clinical studies on endoscopic rectal cancer surgery with focus on randomised controlled trials and systematic reviews. Searches were carried out using medical subject headings $(\mathrm{MeSH})$ and free-text words. The search was limited to studies published in English or German language.

The results of the literature search were sent to the expert panel for assessment of relevance for the clinical practice guidelines (CPG) and critical appraisal.

According to the hierarchy of research evidence [6], we tried to locate randomised controlled trials (RCT, level $1 \mathrm{~b}$ ) or systematic reviews (SR, level 1a) dealing with the key questions. When RCTs were of low quality or completely lacking, non-randomised controlled clinical trials (CCT, level 2) were included. Whenever evidence classified as level 1 or level 2 was scarce, case-control studies or case series (level 3 or level 4) were included.

Formulating recommendations and consensus process

All recommendations were graded according to the quality and quantity of the underlying scientific evidence, the riskbenefit balance and the values expressed by the panellists. The grades of recommendations ranged from A (highquality evidence, usually from RCTs, demonstrating clear benefits) over B (medium-quality evidence and/or disputable risk-benefit ratio) to $\mathrm{C}$ (low-quality evidence and/or unclear risks and benefits). In case of limited or lacking data to support a recommendation the panel decided that the grade of recommendation (GoR) could be higher than the evidence in usual cases would allow. Furthermore, for some recommendations there was a need to modulate and weigh the evidence locally according to value judgements, priorities and local conditions [7].

Based on the identified studies the subgroups formulated draft recommendations. The recommendations were discussed 
and consented in a consensus conference and thereafter presented at the annual congress of the EAES in Geneva, June 17, 2010 in a 90-min plenary session by members of the panel. Notes were taken from the audience after a lively discussion and considered in the further process. A second consensus process (Delphi process) of the recommendations with the explanatory text was necessary due to the changes after the consensus conference. After two Delphi rounds, consensus or strong consensus was reached for the majority of recommendations [8].

Classification of consensus

\begin{tabular}{ll}
\hline Strength of consensus & Percentage of agreement \\
\hline Strong consensus & $>95 \%$ of participants \\
Consensus & $75-95 \%$ of participants \\
Majority & $50-75 \%$ of participants \\
No consensus & $<50 \%$ of participants \\
\hline
\end{tabular}

After final consensus of the recommendations a guideline draft for each topic was written by the subgroups of the expert panel. The manuscripts were collected and completed to a full guideline draft. Finally, the full guideline was consented and adopted by the expert panel. The results are given in the text below.

\section{Recommendations}

Tumour diagnosis and staging

Tumour biopsy with histopathological processing must be conducted prior to start of treatment. (100\% [Strong consensus]; GoR A: 100\% [Strong consensus])

Rectal cancer is diagnosed on the histopathological result of tumour biopsy. In presence of high clinical suspicion (and previous negative biopsy results) core biopsy under general anaesthesia is recommended. Benign pathology may not exclude further surgery in individual cases. Radio- and/or chemotherapy will not start without confirmed pathology.

Preoperative (and pretherapeutic) staging for precise localisation of the tumour must include digital examination and rigid rectoscopy. (100\% [Strong consensus]; GoR A: $100 \%$ [Strong consensus])

Digital rectal examination (DRE) will allow the assessment of tumours within the lower third of the rectum and should be clinically staged according to Mason [9]. DRE is important to evaluate the function of the sphincter and the distance to the anorectal ring in order to evaluate the possibility of doing a sphincter-preserving procedure. Rigid rectoscopy provides a more correct determination of tumour localisation than flexible colonoscopy [10], with an accurate assessment of the distance between the distal edge of the tumour and the dentate line, or alternatively the anal verge.

Assessment of tumour infiltration and local lymph nodes (TN-staging) must be performed prior to any treatment. Endorectal ultrasound and high-resolution magnetic resonance imaging are recommended. (92.9\% [Consensus]; GoR A: $92.9 \%$ [Consensus])

Depth of invasion and lymph node involvement are both important factors for prognosis. In addition, involvement of the mesorectal fascia and tumour invasion of the mesorectal vessels predicts high risk of local recurrence and poor survival [11]. Decision on therapy, especially preoperative treatment, is dependent on accurate tumour staging.

Tumour $\mathrm{T}$ - and $\mathrm{N}$-stage are reliably assessed by both endorectal ultrasound (EUS) and high-resolution magnetic resonance imaging (MRI). Both EUS and MRI have high sensitivity for evaluating T-stage. EUS is superior in discrimination of $\mathrm{T} 1$ and $\mathrm{T} 2$ tumours, and MRI better to evaluate involvement of the mesorectal fascia. Sensitivity for lymph node involvement is lower, but neither of the modalities is significantly superior to the other [12]. A meta-analysis comparing the accuracy of EUS, MRI and computed tomography (CT) was published in 2004 and included 90 studies between 1985 and 2002 [13]. The results demonstrated that EUS and MRI had similar sensitivities for muscularis propria invasion (94\%), but specificity of EUS $(86 \%)$ was significantly higher than that of MR imaging (69\%). Identification and accurate assessment of lymph nodes remains a major challenge. In the metaanalysis, sensitivity estimates for EUS, CT and MR imaging were comparably low (EUS 67\%, MRI 66\% and CT 55\%); specificity values were also comparable $(78 \%$ for EUS, $76 \%$ for MRI and 74\% for CT). An advantage of MRI is the ability to delineate the tumour and its relationship to the mesorectal fascia. High-resolution MRI predicted mesorectal fascia involvement with $92 \%$ agreement [14]. According to the results of the prospective MECURY trial, high-resolution MRI has sensitivity of $94 \%$ and specificity of $92 \%$ for predicting negative circumferential margins (CRM) after surgery [15]. MRI has been shown to be superior compared with CT in local staging of rectal cancer and prediction of mesorectal fascia involvement (MFR) [16].

In conclusion, EUS is most suitable for evaluating early rectal cancer. MRI is recommended in locally advanced rectal tumours, especially to assess mesorectal fascia involvement. The limitations of EUS are a high degree of user dependence and no assessment of stenotic tumours. 
Adequate pretreatment staging must include CT of the abdomen and chest $X$-ray to identify metastatic disease. (83.3\% [Consensus]; GoR A: 85.7\% [Consensus])

Complete staging in patients appropriate for resection (and neoadjuvant therapy) must include physical examination with assessment of performance status, and assessment of the liver and lungs to rule out metastatic disease. Chest X-ray (or alternatively CT scan) and CT of the liver and abdomen (or alternatively MRI or ultrasound) should be performed [17].

Routine use of positron emission tomography (PET) or PET-CT is not indicated unless there is suspicion of synchronous metastatic disease.

(Comment: All panel members recommend assessment of liver and lungs to identify metastatic disease. A majority of the panel favoured the above recommendation including CT of the abdomen instead of ultrasound only for an adequate staging.)

Complete colonoscopy is required to rule out synchronous tumours or other pathologic conditions of colon or rectum. (78.6\% [Consensus]; GoR A: 85.7\% [Consensus])

Pretreatment work-up should include complete colonoscopy to rule out synchronous adenomas and tumours. Synchronous tumours are expected in up to $4 \%$ of all patients presenting with colorectal cancer [18, 19]. Alternatively radiological imaging (e.g. CT colonography or barium enema) can be applied when endoscopy is technically not feasible or tumour stenosis does not allow complete colonoscopy $[20,21]$. In these cases colonoscopy should be performed 3-6 months after surgery.

Pretreatment determination of the tumour marker carcinoembryonic antigen (CEA) should be considered. (92.9\% [Consensus]; GoR B/C: at 50\% [Majority])

According to the American Society of Clinical Oncology (ASCO) 2006 Update of Recommendation for the Use of Tumor Markers in Gastrointestinal Cancer as well as the European Group on Tumour Markers, CEA testing should be ordered preoperatively in patients with rectal cancer. CEA should not be used as a screening test [22, 23]. In rectal as well as in combined colon and rectal cancer population, CEA is an independent prognostic parameter [24, 25]. CEA determination is important as a baseline for postoperative surveillance. Especially an elevated preoperative CEA suggests that the marker would be useful for surveillance. Elevated preoperative CEA will not alter initial treatment strategy or surgical therapy of the primary tumour.

Patient selection and neoadjuvant therapy

There is no indication for preoperative treatment in International Union against Cancer (UICC) stage I tumours. (92.9\% [Consensus]; GoR A: 92.9\% [Consensus])
Outside clinical trials, preoperative treatment in UICC stage I tumours is restricted to very selective individual cases. Organ preservation in ultra-low tumours may be one option.

Neoadjuvant therapy should be provided for patients staged UICC II and III. (92.9\% [Consensus]; GoR B: $85.7 \%$ [Consensus])

Preoperative (instead of postoperative) regimen should be considered in UICC stage II and III rectal cancer. Either combined chemoradiotherapy (CRT) or short-course radiotherapy (scRT) can be used. The main consideration for choosing either of these two options is dependent upon the preoperative MRI staging. If the mesorectal fascia is involved (MRF+), a downsizing effect is important, in which case either CRT or scRT with delayed surgery can be recommended. If the tumour is not at risk of being resected with a positive resection margin, but there is an estimated risk of developing local recurrence, again either of the two schedules can be used [26].

After the endorsement of postoperative adjuvant CRT by a National Cancer Institute consensus conference in 1990, several randomised studies reported lower rates of local failure with preoperative radiotherapy than with surgery alone [27-29]. In addition, a Swedish trial could demonstrate a long-lasting benefit in overall survival compared with surgery alone [30]. After the wide adoption of the concept of total mesorectal excision (TME) as the surgical standard, improvement in local control and survival has been achieved with surgery alone [31]. One of the few studies evaluating preoperative therapy together with documented quality-controlled TME surgery is the Dutch Colorectal Cancer Group study. Preoperative scRT with TME was superior to TME alone in terms of local recurrence, whereas overall survival was similar in the two groups [28, 32]. A Medical Research Council (MRC) trial including 1,350 patients demonstrated a significant reduction of local recurrence in patients receiving preoperative scRT compared with initial surgery with selective postoperative radiochemotherapy $(4.4 \%$ versu $10.6 \%$ after 3 years). In addition, a relative improvement in diseasefree survival has been shown, whereas overall survival did not differ between the groups [33]. A number of randomised trials demonstrated the effectiveness of CRT (either post- or preoperatively). To our knowledge, there has been no prospective study comparing preoperative CRT with quality-controlled TME surgery alone. Two trials have compared preoperative treatment with postoperative one. The Uppsala trial demonstrated superiority in reduction of local recurrence rate with scRT versus postoperative longcourse irradiation [34]. Moreover, the German Rectal Cancer Study demonstrated the superiority of the neoadjuvant approach over postoperative treatment. Preoperative 
therapy was associated with a significant reduction in local recurrence and treatment-associated toxicity [35].

Both preoperative scRT and neoadjuvant CRT provide increased local control of rectal cancer. Still, there is much debate in Europe about the two different approaches. The results from the small study of the Polish Colorectal Study Group comparing scRT and CRT showed no evidence of a difference in the rates of sphincter-preserving surgery or local recurrence, however this study was not statistically powered to address local recurrence [36]. Outcome data from an Australian trial as well as a recently closed German trial comparing both preoperative treatment strategies are still awaited, but preliminary data indicate similar results to the Polish trial $[37,38]$.

Patients with T4-staged disease where downsizing is an issue should be treated with preoperative combined radiochemotherapy.

Standard preoperative CRT combines radiation with a dose of 46-50.4 Gy with 5-fluorouracil (5-FU) chemotherapy given either as bolus injections with Leucovorin, prolonged continuous infusion (likely better than bolus) or oral capecitabine [39-41]. Combined CRT is followed by TME surgery 6-8 weeks later.

Preoperative scRT consists of single doses of $5.0 \mathrm{~Gy}$ in five fractions within 1 week up to a total dose of $25 \mathrm{~Gy}$. TME surgery should be performed within 10 days from start of radiotherapy [42]. If this schedule is not possible to follow, surgery should be postponed to 8 weeks later [43].

Besides oncological limitations, there are no contraindications for laparoscopic surgery compared with open surgery. Morbid obesity or cardiopulmonary impairment is not a contraindication to laparoscopic rectal cancer surgery but may require additional perioperative evaluation and monitoring. (92.9\% [Consensus]; GoR B: $92.9 \%$ [Consensus])

The panel refers to the previous EAES clinical practice guidelines on laparoscopic resection of colonic cancer (2004, update 2006) and on pneumoperitoneum for laparoscopic surgery (2002, update 2006) [44].

\section{Perioperative management}

Explicit data on bowel preparation before laparoscopic TME-either in favour or against-do not exist. (100\% [Strong consensus]; GoR C: 100\% [Strong consensus])

For colon cancer, there is some evidence that bowel preparation does not reduce complications (e.g. anastomotic leakage, surgical-site infections etc.) In addition, there is a trend for increased complications for patients undergoing bowel preparation [45-47]. The largest metaanalysis, including almost 5,000 patients, demonstrated with a high level of evidence that all kinds of mechanical bowel preparation should be omitted before colonic surgery [46].

For rectal cancer alone, explicit data do not exist. However, in any case after low anterior rectal resection where a deviating stoma is performed, bowel preparation seems to be a logical prerequisite. The necessity of a protective stoma in patients undergoing low anterior resection with TME is still discussed. A randomised controlled trial conducted by Ulrich et al. evaluated the need for diverting ileostomy in those patients. Even if the number of patients included in this study was quite small, they could demonstrate a significantly higher number of symptomatic anastomotic leakages in the non-stoma group compared with the stoma group [48]. The results of a larger randomised trial by Matthiesen et al. strongly support a diverting stoma after low anterior resection [49]. As there are many more arguments in favour of a deviating stoma after low rectal resection in open surgery, bowel preparation can be considered in these cases.

However, data from a subgroup analysis of a large multicentre trial did not show an influence of bowel preparation for cancer of the mid rectum [50]. These data are supported by Bretagnol, even if not significant [51].

Epidural catheter can be considered for pain management. (100\% [Strong consensus]; GoR C: 100\% [Strong consensus])

For open colon surgery, there is quite some evidence in favour of epidural analgesia, but for the laparoscopic approach it is still discussed [52]. Use of epidural or i.v. patient-controlled analgesia (PCA) has been extensively investigated in open surgery, but there is a paucity of data comparing the various analgesic regimes available in laparoscopic surgery. The enhanced recovery program (ERP) has increasingly been used for laparoscopic surgery in its unmodified form with thoracic epidural. While some centres are using this modality, other units are using PCA, and alternative forms of postoperative pain control are being investigated. Results of a systematic review have highlighted the relative lack of evidence comparing outcomes between differing analgesic regimes. At present, there is no convincing evidence to suggest the superiority of either PCA or epidural in terms of length of hospital stay for laparoscopic colorectal surgery. In the short term, no significant difference has been identified in terms of adverse events, although postoperative pain appears better controlled in the epidural group [53].

See also www.postoppain.org, and the PROSPECT study group.

Opioid-like drugs should be avoided. (100\% [Strong consensus]; GoR B: 100\% [Strong consensus])

While opioids still remain the mainstay for postoperative analgesia worldwide, their use can be associated with adverse effects, including ileus, which can prolong hospital 
stay. A number of studies have investigated the use of nonopioid-like analgesics and regimens. A systematic review by McCarthy et al. determined the overall efficacy of different analgesic regimens on postoperative analgesia and recovery from surgery in patients undergoing various surgical procedures. Relevant data such as return of bowel function, length of hospital stay, intraoperative anaesthetic requirement and adverse effects were also compared. Patients receiving non-opioid-like drugs had more rapid return to normal bowel function and decreased length of hospital stay. Thus, opioid-like drugs, even if highly efficient in pain control, should be avoided due to their negative effect on bowel function $[54,55]$.

Currently, there are no evidence-based recommendations for a distinct perioperative volume management. "Fast-track" concepts should be considered. (100\% [Strong consensus]; GoR C: 85.7\% [Consensus])

The main goal of perioperative volume management is to keep homeostasis normal. Although the ideal volume and content of solutions for perioperative intravenous infusion are still unknown, there is evidence that excessive intravenous fluid administration in the perioperative phase has a negative impact on postoperative outcome [56-59]. According to the meta-analysis of Rahbari et al., restrictive rather than standard fluid amount reduces morbidity after colorectal resection [60].

Patients undergoing rectal surgery must receive antibiotic prophylaxis. The antibiotic must be administered before surgery (single dose) and should cover against both aerobic and anaerobic bacteria. (100\% [Strong consensus]; GoR A: 100\% [Strong consensus])

Research shows that administration of prophylactic antibiotics before colorectal surgery reduces the risk of postoperative surgical wound infection (SWI). The best antibiotic choice, timing of administration and route of administration remain undetermined [61]. The Cochrane review by Nelson et al., including 182 trials (30,880 participants) and 50 different antibiotics, demonstrated a statistically significant difference in postoperative SWI when prophylactic antibiotics were compared with placebo/no treatment [relative risk (RR) $0.30,95 \%$ confidence interval (CI) $0.22-0.41]$. No statistically significant differences were shown when comparing short- and long-term duration of prophylaxis (RR 1.06, 95\% CI 0.89-1.27), or singledose versus multiple-dose antibiotics (RR 1.17, 95\% CI 0.67-2.05). Additional aerobic coverage and additional anaerobic coverage both showed statistically significant improvements in SWI rates (RR 0.41, 95\% CI 0.23-0.71 and RR 0.55 , 95\% CI 0.35-0.85, respectively), as did combined oral and intravenous antibiotic prophylaxis when compared with intravenous alone (RR 0.55, 95\% CI $0.41-0.74$ ) or oral alone (RR $0.34,95 \%$ CI $0.13-0.87$ ). Established gold-standard regimens were no less effective than any other antibiotic choice. Therefore, antibiotics covering aerobic and anaerobic bacteria must be delivered orally and/or intravenously prior to colorectal surgery, and one dose is sufficient [61].

Currently, there are no evidence-based recommendations for a distinct postoperative diet. "Fast-track" concepts should be considered. (100\% [Strong consensus]; GoR C: $92.9 \%$ [Consensus])

Several randomised, controlled trials showed that early oral/enteral feeding at will did not increase morbidity and did reduce length of stay (LOS). Nausea and vomiting can be more frequent but do not lead to increased morbidity as well $[62,63]$.

See also the Consensus Review of Optimal Perioperative Care in Colorectal Surgery [64].

Operative techniques

Patient must be well fixed and placed in lithotomy position with legs in padded, adjustable stirrups. (92.9\% [Consensus]; GoR A: 85.7\% [Consensus])

Patient should be placed in modified lithotomy position. The legs are placed in padded, adjustable stirrups. The thighs have to be at the level of the abdominal wall with the knees slightly flexed. Higher elevation may cause difficulties in manoeuvring instruments. The patient is positioned so that the perineum is reachable from between the legs. This allows the surgeon free access to the anus and rectum for intraoperative endoscopy, pelvic manipulation, perineal resection or transanal anastomosis. These are sound principles based on experience, although not tested by randomised trial.

It is important to place the patient carefully on the operating room (OR) table, fixed according to local regulations and in such a way that introduction of the circular stapler through the anus can be safely performed.

Operating table has to be capable of steep Trendelenburg and reverse Trendelenburg positions and right and left rotation. (100\% [Strong consensus]; GoR A: 85.7\% [Consensus])

Again there is no evidence from any randomised trial; the recommendation is based on the experience of the panel. The Trendelenburg position is used to keep the small bowel out of the operating field during the procedure. Both arms are tucked, padded and protected along the patient's side.

A catheter is introduced into the bladder. (85.7\% [Consensus]; GoR A: 78.6\% [Consensus])

As an alternative to transurethral catherization, suprapubic catheterization may be used. There is no evidence that one is better than the other [65].

Positioning of the surgeon and assistants as well as trocar position are based on the experience and the 
preference of the individual surgeon. (100\% [Strong consensus]; GoR C: $100 \%$ [Strong consensus])

The most commonly used OR setting is a set of two monitors; one is placed at the level of the patient's left shoulder and the other at the left foot level of the patient. The surgeon and the first assistant stand at the patient's right side, and the nurse is positioned between the patient's legs. A second assistant stands at the left side of the patient.

After insufflation, four or five ports are used: one for the laparoscope, held by the first assistant; two for the operating surgeon, introduced in the right lower abdomen for instruments and endo-staplers. The fourth port is introduced left laterally at the level of the umbilicus, and a fifth trocar will be introduced in the left upper abdomen to mobilize the splenic flexure. During dissection of the rectum deep in the pelvis, another trocar may be introduced above the pubis to assist the anterior aspect of dissection.

There is no clear recommendation for a distinct device, whether bipolar or ultrasonic. Ultrasonic and advanced bipolar devices as well as surgical stapling devices may reduce blood loss and shorten operating time. (100\% [Strong consensus]; GoRA: 85.7\% [Consensus])

Dissection may be performed by means of electrocautery, ultrasonic scalpel or bipolar electrothermal device.

Most data are derived from laparoscopic colon surgery, where it has been shown that high-energy power sources specifically adapted for endoscopic surgery reduce operative time and blood loss [66-69]. These data can be transferred to laparoscopic rectal cancer surgery. Morino et al. conducted a prospective randomised trial in patients undergoing laparoscopic colorectal surgery, comparing ultrasonic dissection (UC) with standard electrocautery. Forty of 146 randomised patients underwent low anterior resection. Operative time was less with UC, but did not differ significantly between the two groups, whereas intraoperative blood loss was significantly less with UC [70]. Zhou et al. studied 40 patients with rectal cancer scheduled for TME, randomly divided into ultrasonic scalpel or monopolar electrocautery shovel (ES). This study showed no significant difference in blood loss, but ES may generate heavy smog. Furthermore, ES can produce a higher surface temperature when managing tissues [71].

In all cases of low anterior resection the splenic flexure should be mobilized. (78.6\% [Consensus]; GoR B: $71.4 \%$ [Majority])

This is a general rule, but in selected cases, the length of the sigmoid loop will influence the choice. A long loop may in some cases preclude mobilization. The splenic flexure should be mobilized when needed to ensure a tension-free anastomosis. Experience suggests that this is better done at the beginning of the operation; before dissection of the rectum, the left mesocolon and the sigmoid mesocolon are dissected from medial to lateral, starting behind the inferior mesenteric vein. The underlying retroperitoneal structures, including gonadal vessels, left ureter and Gerota's fascia, are left in place. Dissection is continued orally up to the pancreas into the lesser sac and laterally along the fascia of Toldt on to the peritoneal attachments of the left colon. After dividing the inferior mesenteric vein under the pancreas and the inferior mesenteric artery (IMA), complete mobilization is achieved by lateral dissection and mobilization of the splenic flexure and the descending colon and freeing the greater omentum from the transverse colon. Dissection will proceed with medial dissection of distal sigmoid and rectum [2-15].

Unexpected locally advanced tumour (T4) should lead to conversion. (100\% [Strong consensus]; GoRB: $85.7 \%$ [Consensus])

As in open surgery, oncological principles (resection margins, high vessels ligation, lymphadenectomy etc.) should be respected by the laparoscopic approach. (92.9\% [Consensus]; GoRB: 92.9\% [Consensus])

The main goal is a tumour-free margin. Whenever possible a free margin should be obtained. (92.9\% [Consensus]; GoRB: $85.7 \%$ [Consensus])

Pelvic dissection and rectal mobilization must be performed according to TME principles. (100\% [Strong consensus]; GoRA: 92.1\% [Consensus])

These are universally accepted oncological statements and are common sense for both open and laparoscopic surgery [72-74]. T4 tumours have been excluded from all randomised studies in laparoscopic colon and rectal cancer surgery. In individual cases it may be possible to proceed with the laparoscopic approach, e.g. in limited T4 situation where en bloc resection with small bowel or tangential/ partial resection of the bladder will allow safe resection with free margins.

From medial to lateral, the rectum is dissected free on its right side and posteriorly as far as possible. The pelvic autonomic nerve plexus, the superior hypogastric sympathetic nerves are carefully dissected from the mesorectum and preserved. Anteriorly, dissection will start at the level of the seminal vesicles in the male patient or recto-vaginal septum in the female patient, usually after traction of the uterus by a percutanously introduced needle.

Pelvic dissection proceeds, according to TME principles, alternating posterior, lateral left and right and anterior dissection, along the seminal vesicles, Denonvillier fascia and the prostate in the male or along the recto-vaginal septum in the female patient. It is important is to preserve the parasympathetic sacral nerve roots from S2 to S4. Dissection proceeds down to the pelvic floor [75-88].

If the tumour is located in the midrectum, the rectum should be transected at the level of the pelvic floor followed by a double-stapling anastomosis. (100\% [Strong consensus]; GoRB: 100\% [Strong consensus]) 
The rectum is transected at the level of the pelvic floor by means of a roticulating endostapler device [75-88], using as few cartridges as possible. Use of more than two cartridges has been reported to result in a higher anastomotic leakage rate $[89,90]$. After rectal division, usually a port site in the right lower abdomen is extended to $5-7 \mathrm{~cm}$, and adequately protected to deliver the specimen. Alternatively, a small Pfannenstiel incision is used. Once the specimen is exteriorised, division of the remaining mesentery and the marginal artery are completed and the anvil inserted. After closure of the wound or temporary closure of the protection device, pneumoperitoneum is re-established and a double-stapling anastomosis accomplished (after introduction of the stapler device transanally). Control of the anastomosis should always be performed by either endoscopy, methylene blue or instillation of air under saline solution. The presacral space should be drained [91] and a protective stoma created [92].

The difficulty of performing the transection is still a point of concern. Some authors argue that it is always possible to transect the rectum at this level, independently of the angle of the rectum and the abdominal wall. Eventually introduction of the endostapler through a suprapubic trocar may help to do this adequately at this level [79]. In a narrow male pelvis with a reasonably big tumour located in the mid or proximal low rectum, this action may be difficult to accomplish. Difficulties in achieving this are variable, being related to high body mass index (BMI), tumour size, distance from the anal verge and characteristics of the pelvic outlet. These factors may be considered to be related to anastomotic leakage and morbidity [93, 94]. Moreover, some authors argue that an optimal perpendicular transection of the rectum during laparoscopic TME is impossible or very demanding to achieve with the available $45^{\circ}$ angulation roticulating stapling devices and that the optimal angulation for this ideal transverse transection will vary between 62 and $68^{\circ}$ [95]. Some surgeons will, to achieve this at the proper place, prefer to palpate the tumour before transection. They will prefer at this stage to make a Pfannenstiel incision and to apply manually the conventional roticulator-contour device properly below the tumour [26]. Double-stapling anastomosis will be done as mentioned above. Use of a small Pfannenstiel incision to perform the anastomosis at this stage should not be considered as conversion [96, 97].

Laparoscopic intracorporeal dissection means that the dissection, the division of the vessels, the transection of the rectum and the anastomosis must be performed laparoscopically. (85.7\% [Consensus]; GoR A: 85.7\% [Consensus])

Intracorporeal dissection means that the dissection, the division of the vessels, the transection of the rectum and the anastomosis are all performed laparoscopically. If dissection of the rectum has to be completed through a wide Pfannenstiel incision, this is considered conversion to laparotomy. Once dissection is completed laparoscopically, use of a small Pfannenstiel incision for performing the anastomosis is not considered as conversion.

Dissection is mostly performed medial to lateral. Dissection may be performed by means of electrocautery, ultrasonic scalpel or bipolar electrothermal device. After visualization of the left ureter, the IMA is dissected free and is divided between clips, endostapler or sealing device at high or low tie level. Low tie level will permit preservation of the left colonic artery and better protection of the hypogastric plexus on the aorta [71, 75-88].

For this laparoscopic procedure, there are alternatives such as hand-assisted ultra-low resection [98] one handsize incision surgery [99] and robot-assisted rectum laparoscopic resection [100-102].

Some authors have used intraoperative radiotherapy during the laparoscopic TME in order to reduce the local recurrence rate in locally advanced rectal cancer [103]. Furthermore in cases of difficult dissection in which conversion is considered necessary, laparoscopic mobilization of the splenic flexure followed by rectal dissection through a Pfannenstiel incision will reduce operative trauma and decrease morbidity [104].

All these variations must be regarded as experimental and cannot be recommended until further evidence.

A continent patient with low rectal cancer, 3-4 cm from anal verge, with no infiltration into the pelvic floor and external sphincter can be approached by transanal intersphincteric dissection and coloanal anastomosis. (100\% [Strong consensus]; GoR C: 100\% [Strong consensus])

In a patient with incontinence a low Hartmann procedure should be considered. (100\% [Strong consensus]; GoR C: $92.9 \%$ [Consensus])

In very distal rectal cancer, e.g. 3-4 cm from anal verge, with no in-growth of tumour in the pelvic floor or external sphincter and with good continence grade, a coloanal anastomosis should be considered. In this case, dissection of the rectum will be continued through the pelvic floor to reach the level of the sphincters [78, 84, 85].

Considering a low Hartman procedure in patients preoperatively not continent for stool is a sound concept, although no studies investigating this subject exist [105].

Transanal intersphincteric dissection should be performed proximal from the dentate line and below the tumour. (92.9\% [Consensus]; GoR B: 85.7\% [Consensus])

Dissection should be performed proximal from the dentate line and below the tumour. Using the anal Scott spreading device (lone star) the anus and distal rectum are exposed, and the rectum transected proximal to the dentate line after intersphincteric dissection. The specimen can be retrieved through a small Pfannenstiel incision or through the anus, and an end-to-side or $\mathbf{J}$ pouch anastomosis is 
performed [74, 85, 106, 107]. The presacral space should be drained and a defunctioning loop ileostomy created to protect the anastomosis [91, 92].

No recommendation concerning the construction of a colonic pouch can be made. There are no specific data for laparoscopic surgery. In open surgery the use of a colonic pouch guarantees better function in the first 12-18 months and in the long term. (92.9\% [Consensus]; GoR C: 92.9\% [Consensus])

Controversy exists about the type of anastomosis to use in low anterior resection and coloanal anastomosis: straight anastomosis, J pouch anastomosis, transverse coloplasty or end-to-side anastomosis [106-111]. One review concludes that probably end-to-side anastomosis will result in the same functional quality of life as pouch anastomosis [109].

The advantages of the construction of a colonic pouch after rectal resection in the laparoscopic setting should be the same as in open surgery. Construction of a pouch in the laparoscopic setting seems not to be more difficult than in open surgery [108].

Concerning a deviating stoma there are no specific data for laparoscopic surgery. In open surgery a deviating stoma reduces the rate of symptomatic leakage/fistula. (78.6\% [Consensus]; GoR B: 85.7\% [Consensus])

Data from open rectal cancer surgery demonstrate that a deviating stoma reduces the rate of symptomatic leackage/ fistula. Metanalysis and review of currently published studies show the advantages of the ileostomy [48]. A large Swedish randomised trial showed a reduction in leak rate in patients with stoma and a better long-term outcome [49]. Therefore, a deviating stoma is recommended when performing TME in rectal cancer surgery. These data should be extrapolated to laparoscopic surgery. In laparoscopic surgery, results of comparative trials in similar clinical situation show a reduction in the intensity of peritonitis when the anastomosis is diverted or not [112]. Especially after neoadjuvant chemoradiotherapy a stoma (ileostomy or colostomy) is advisable in laparoscopic rectal cancer surgery.

Very low rectal cancer, with infiltration into the external sphincter or pelvic floor, should be treated by APR. (85.7\% [Consensus]; GoR B: 92.9\% [Consensus])

Classical APR implies a laparoscopic mobilization of the rectum followed by perineal resection in lithotomy position. Prone position for the perineal cylindrical excision is proposed. (85.7\% [Consensus]; GoR C: $92.9 \%$ [Consensus])

Mobilization of the rectum by laparoscopy has to be performed as deep as possible in the pelvic floor, to a level where there is no risk of compromising the surgical plane [113-118].

There are two different approaches for the perineal phase: the classical perineal resection between the legs in lithotomy position, and the extralevator perineal resection performed in prone position [119]. During the first approach the perineal excision is performed, the specimen resected and retrieved (waist model), presacral space drained and wound approximated in layers, whereas in the extralevator excision the resected specimen has cylindrical shape. It is currently suggested that R0 resections and circumferential resection margins (CRM) involvement are improved in the extralevator resection [120].

The defect after perineal excision can be approximated, whereas after extralevator dissection it can be closed by means of a muscular flap. (92.9\% [Consensus]; GoR C: 92.9\% [Consensus])

In lithotomy position, closure methods to occlude the pelvis can include the use of the greater omentum, closure of the peritoneum or leaving the peritoneum and the pelvis open. To close a huge perineal defect after extralevator excision, reconstruction of pelvic floor will be accomplished by means of unilateral or bilateral $\mathrm{m}$. gluteus maximus flap reconstruction, a vertical $\mathrm{m}$. rectus abdominis flap or a transverse m. rectus abdominis flap [121]. Other possibilities of reconstruction such as use of prosthetic materials are considered as exceptional and routinely not recommended.

Quality and outcome analysis

Laparoscopic approach for curative rectal cancer must offer the same quality of the surgical specimen as in open surgery. Pathology analysis must include assessment of the following: completeness of the mesorectum, CRM, distal margin and number of lymph nodes. (100\% [Strong consensus]; GoR A: 92.9\% [Strong consensus])

Laparoscopic approach to TME is not inferior to the open in terms of disease-free survival (DFS), overall survival (OS) or local recurrence. (92.9\% [Consensus]; GoR B: $85.7 \%$ [Consensus])

The final goal in rectal cancer surgery using total mesorectal excision is to reduce the incidence of local recurrence to a minimum rate. Current results of multiple singlecentre and multicentre experiences in open surgery established a recurrence rate below 5-7\% [32, 35]. The initial results obtained from single-centre experiences show the ability of laparoscopic approach to obtain mesorectal specimens that achieve the standards of pathology quality and a local recurrence rate below $6 \%$. In a recent study analysing the Spanish registry of rectal cancer there were no differences in the quality of the mesorectum between the open and the laparoscopic approach. Six hundred four patients operated between 2006 and 2008 (209 laparoscopic and 395 open) were included. This study did not show differences in the number of lymph nodes retrieved, status of the CRM or in the quality of the mesorectum 
(complete $77 \%$, nearly complete $15 \%$, incomplete $8 \%$ ). However, the shortcomings of this study are diverse: it is a voluntary registry, not randomised and obviously selected, with more difficult cases included in the open group [122]. In a recent single-center prospective randomised trial Lujan et al. could not find any differences in the quality of the mesorectum or in the rates of local recurrence [88]. However, these trials still have the drawbacks of selection bias, and this topic should be analysed carefully in multicenter prospective randomised trials that would permit to demonstrate the safety of the laparoscopic approach to low rectal cancer.

The laparoscopic approach permits to obtain similar long-term outcome, in terms of disease-free or overall survival, as in open surgery. Table 1 presents the long-term outcome from the most important series observed up to now, showing DFS, OS and local recurrence similar to open surgery. Recently, Laurent et al. [123] presented outcome data from a comparative study including 500 patients (Tables 1,2). The main results of this study were the absence of differences in relation to local recurrence (LR) and DFS. Additionally this study reported that the type of approach did not influence the cancer outcome, as well as that the conversion $(36 / 238,15 \%)$ did not have a negative impact on postoperative mortality, local recurrence or survival [123].

Laparoscopic resection is slightly superior to open in terms of short-term outcome (reduced hospital stay, improved bowel function and reduced pain). (92.9\% [Consensus]; GoR B: 85.7\% [Consensus])

Initial results show that laparoscopic approach to rectal cancer is followed by the accepted advantages of endoscopic surgery in terms of less pain, faster recovery and better immediate outcome compared with open cases. Breukink et al. [124] published in 2006 a metanalysis of 48 studies including 4,224 cases. The quality of the trials included in this metanalysis were diverse [ 3 grade $1 \mathrm{~b}$ (individual randomised trial), 12 grade $2 \mathrm{~b}$ (individual cohort study), 5 grade $3 b$ (individual case-control study) and 28 grade 4 (case series)]. This meta-analysis did not show differences in DFS, LR, mortality, morbidity, leakage, CRM or number of lymph nodes. Laparoscopic TME was associated with less blood loss, faster return to normal diet, less pain, less narcotic use and less immune response. On the other hand the laparoscopic approach was followed by longer operative time and higher costs. The conclusion of this analysis was that the laparoscopic approach appeared to have clinically short-term advantages in patients with primary resectable rectal cancer. The longterm impact on oncological endpoints awaits the findings from large ongoing randomised trials. Table 2 reports the results of the more important series published.

Laparoscopic resection is superior to open in terms of reduced surgical-site infections. (92.9\% [Consensus]; GoR B: 85.7\% [Consensus])

Two recent studies $[125,126]$ have shown the definitive advantage of laparoscopic approach in terms of incidence and severity of postoperative surgical-site infection (SSI). Varela et al. [125] have recently observed in a large cohort of patients [laparoscopic $(n=94,665)$ or open $(n=36,965)$ appendectomy, cholecystectomy, antireflux surgery or gastric bypass between 2004 and 2008]. Overall, the incidence of SSI was significantly lower in laparoscopic $(483$ of $94,665,0.5 \%)$ than in open $(669$ of 36,965 , $1.8 \%)$ surgery $(p<0.01)$. The study permits to conclude that patients treated with laparoscopic procedures are less likely to experience SSI. After stratification by severity of illness, admission status and wound classification, laparoscopic techniques showed a protective effect against SSI. In another recent study [126] Dobson et al. analysed the need for emergency department evaluation, hospital readmission and re-operation after colorectal surgery in 603 laparoscopic versus 2,246 open patients prospectively recorded. Although SSI was identified in $5.8 \%$ of the laparoscopic group and $4.8 \%$ in the open group, emergency department evaluation for infection was needed in only $24 \%$ of the laparoscopic patients versus $42 \%$ in open surgery. Also hospital readmission (1\% laparscopic versus

Table 1 Laparoscopic rectal cancer surgery, long-term oncological outcome: follow-up, 5-year overall survival (OS), 5-year disease-free survival (DFS), local recurrence (LR) and type of study with level of evidence (LoE)

\begin{tabular}{|c|c|c|c|c|c|c|c|}
\hline & $N$ & $\begin{array}{l}\text { Follow-up } \\
\text { (months) }\end{array}$ & $\begin{array}{l}5-\text { Year OS } \\
(\%)\end{array}$ & $\begin{array}{l}\text { 5-Year DFS } \\
(\%)\end{array}$ & $\begin{array}{l}\mathrm{LR} \\
(\%)\end{array}$ & Type of study & LoE \\
\hline Anthuber [152] 2003 & 101 & 17 & - & - & 2 & Individual cohort study & $2 b$ \\
\hline Morino [78] 2003 & 70 & 45.7 & 74 & 63 & 4.2 & Case series & 4 \\
\hline Leroy [80] 2004 & 98 & 36 & 65 & 75 & 6 & Case series & 4 \\
\hline Tsang [153] 2006 & 105 & 26.9 & 76.9 & 64.4 & 8.9 & Case series & 4 \\
\hline Agha [154] 2008 & 225 & 46.4 & 69.2 & 85.7 & 5.8 & Case series & 4 \\
\hline Laurent [123] 2009 & $238 / 233$ & 52 & $83 / 72$ & $82 / 79$ & $3.9 / 5.5$ & Individual case-control study & $3 b$ \\
\hline Laparoscopy/Open & & & & & & & \\
\hline
\end{tabular}


Table 2 Laparoscopic rectal cancer surgery, short-term outcomes: operating time (OP-time), conversion rate, hospital stay, mortality, morbidity and type of study with level of evidence (LoE)

\begin{tabular}{|c|c|c|c|c|c|c|c|c|}
\hline & $N$ & $\begin{array}{l}\text { OP-time } \\
(\mathrm{min})\end{array}$ & $\begin{array}{l}\text { Conversion } \\
(\%)\end{array}$ & $\begin{array}{l}\text { Hospital stay } \\
\text { (days) }\end{array}$ & $\begin{array}{l}\text { Mortality } \\
(\%)\end{array}$ & $\begin{array}{l}\text { Morbidity } \\
(\%)\end{array}$ & Type of study & LoE \\
\hline $\begin{array}{l}\text { Quah [151] } 2002 \\
\text { Laparoscopy/Open }\end{array}$ & $86 / 84$ & - & 12 & - & - & - & RCT & $1 b$ \\
\hline $\begin{array}{l}\text { Anthuber [152] } 2003 \\
\text { Laparoscopy/Open }\end{array}$ & $101 / 334$ & $218 / 219$ & 10.9 & $14.4 / 19.9$ & $0 / 1.5$ & $30.7 / 65$ & Individual cohort study & $2 b$ \\
\hline Morino [78] 2003 & 100 & 250 & 12 & 16.6 & 2 & 36 & Case series & 4 \\
\hline Rullier [111] 2003 & 32 & 420 & 9.3 & 9 & 3.1 & 31.2 & Individual cohort study & $2 b$ \\
\hline Leroy [80] 2004 & 102 & 202 & 3 & 11.9 & 2 & 27 & Case series & 4 \\
\hline Tsang [153] 2006 & 105 & 170 & 1.9 & 10.1 & 0 & 24.7 & Case series & 4 \\
\hline Agha [154] 2008 & 225 & 217 & 10.2 & 13.8 & 1.3 & 35.6 & Case series & 4 \\
\hline $\begin{array}{l}\text { Laurent [123] } 2009 \\
\text { Laparoscopy/Open }\end{array}$ & $238 / 233$ & - & 15.1 & $9 / 16$ & $0.8 / 2.6$ & $32 / 37.7$ & Individual case-control study & $3 b$ \\
\hline
\end{tabular}

$52 \%$ open) and re-operation ( $0 \%$ laparoscopic versus $12 \%$ open) were both significantly less common and permitted to conclude that laparoscopic colorectal surgery patients experienced less severe morbidity when they developed SSI and required fewer healthcare resources to manage their wounds compared with open colorectal surgery patients.

Postoperative morbidity rate after laparoscopic approach to the rectum seems to be similar/slightly lower than after open surgery. (85.7\% [Consensus]; GoR B: $85.7 \%$ [Consensus])

Postoperative morbidity after laparoscopic approach to the rectum seems to be similar/slightly lower than after open surgery. This issue cannot be definitively assessed until the results of large multicenter RCT are available. A cautionary note should be commented in relation to the anastomotic leak rate, in relation to the difficulty observed for low rectal transection in the obese or in those with a narrow pelvis space. As commented before, surgical-site infections are expected to be lower when the laparoscopic approach is used.

The laparoscopic approach permits to obtain a similar sphincter-preservation rate, without impact on the number of definitive stoma. (92.9\% [Consensus]; GoR B: $85.7 \%$ [Consensus])

The lack of adequately powered RCT does not permit to definitively conclude whether the laparoscopic approach to rectal cancer is associated with a similar rate of sphincter preservation or definitive stoma. Preliminary results from single series and RCT do not show any differences regarding the rate of definitive stoma, and due to the better visualization of the deep pelvis, the number of sphincter preservations may be increased.

There are no definitive data in relation of quality of life (QoL) after laparoscopic surgery of the rectum; however, data extrapolated from trials including rectosigmoid resection seem to confer a slight short-term improvement of QoL after laparoscopic surgery. (92.9\% [Consensus])

It is well established that, after colorectal laparoscopic surgery, immediate QoL is superior to that after open surgery [127-129]. This advantage may be extrapolated to low rectal cancer cases, mainly because some of these trials included rectosigmoid resections, but there are no data available in relation to rectal surgery. A logical inference is to assume that this improvement could be extrapolated to rectal surgery, but in this situation, the most detrimental to QoL are the existence of a stoma or poor anorectal function, aspects that are not related intrinsically to the laparoscopic approach. For all these reasons, further specific information regarding this clinical point is necessary.

Anorectal function has a similar outcome after laparoscopic and open surgery. Laparoscopic pelvic dissection may impair genitourinary function after rectal resection, like open surgery. Sexual function is a point of concern. (92.9\% [Consensus])

Pelvic exploration is improved by the laparoscopic approach due to better visualization of the structures, but identification of the tiny nervous structures especially in the lower pelvis continues to be hazardous. On the other hand the need for retraction as well as energy sources used in laparoscopic surgery may impair/cause injury to deep pelvic structures. Laparoscopic pelvic dissection may impair bladder function after rectal resection, like in open surgery. Sexual function is a point of concern, and several studies have shown detrimental effects on postoperative sexual function, but without a clear consensus (Table 3).

There is a lack of information in relation to anorectal function after laparoscopic dissection of the rectum. Anorectal function is severely impaired by previous radiotherapy, but the laparoscopic approach does not seem to impair/improve this function. Further studies focussed on 
Table 3 Laparoscopic rectal cancer surgery, post-operative urinary and sexual function: year of publication, type of study and level of evidence (LoE)

\begin{tabular}{|c|c|c|c|c|c|}
\hline & $\begin{array}{l}\text { Year of } \\
\text { publication }\end{array}$ & Urinary function & Sexual function & $\begin{array}{l}\text { Type of } \\
\text { study }\end{array}$ & LoE \\
\hline Quah [151] & 2002 & No significant deterioration & Impaired in male, but not in female & $\mathrm{RCT}$ & $1 \mathrm{~b}$ \\
\hline $\begin{array}{l}\text { Laparoscopy/ } \\
\text { Open }\end{array}$ & & No differences lap versus open & $\begin{array}{l}\text { Subgroup of sexually active male significantly impaired in } \\
\text { lap versus open }\end{array}$ & & \\
\hline Jayne $[155]$ & 2005 & Bladder dysfunction (global) in & Impaired & $\mathrm{RCT}$ & $1 \mathrm{~b}$ \\
\hline $\begin{array}{l}\text { Laparoscopy/ } \\
\text { Open }\end{array}$ & & $\begin{array}{l}35 \% \\
\text { No differences lap versus open }\end{array}$ & $\begin{array}{l}\text { In male, overall sexual function }+ \text { erectile function tended } \\
\text { to be worse in lap versus open }\end{array}$ & & \\
\hline Liang [156] & 2007 & $\begin{array}{l}\text { Voiding function- }-71.6 \% \\
\text { good, } 23 \% \text { fair, } 5.4 \% \text { poor }\end{array}$ & $\begin{array}{l}\text { Female }-53.6 \% \text { good, } 14.3 \% \text { fair, } 32.1 \% \text { poor } \\
\text { Male-ejaculation/potency-56.3/62.5\% good, } 18.7 / 14.3 \% \\
\text { fair, } 25 / 21.9 \% \text { poor }\end{array}$ & $\begin{array}{l}\text { Case } \\
\text { series }\end{array}$ & 4 \\
\hline $\begin{array}{l}\text { Breukink } \\
\text { [157] }\end{array}$ & 2008 & $\begin{array}{l}\text { Quality of life due to urinary } \\
\text { symptoms significantly } \\
\text { decreased } \\
\text { With regard to specific } \\
\text { symptoms, only frequency } \\
\text { significantly worsened }\end{array}$ & No significant differences except of intercourse satisfaction & $\begin{array}{l}\text { Case } \\
\text { series }\end{array}$ & 4 \\
\hline $\begin{array}{l}\text { Asoglu [158] } \\
\text { Laparoscopy/ } \\
\text { Open }\end{array}$ & 2009 & No differences & $\begin{array}{l}\text { Significantly higher rate of sexual dysfunction in open } \\
\text { versus lap (in both female and male) }\end{array}$ & $\begin{array}{l}\text { Individual } \\
\text { cohort } \\
\text { study }\end{array}$ & $2 b$ \\
\hline Morino [159] & 2009 & $\begin{array}{l}\text { No significant differences, } \\
\text { except for a postoperative } \\
\text { weak stream }\end{array}$ & $\begin{array}{l}\text { Sexual desire was maintained by } 55.6 \% \text {, ability to engage in } \\
\text { intercourse by } 57.8 \% \text {, and ability to achieve orgasm and } \\
\text { ejaculation by } 37.8 \% \text { of the male patients }\end{array}$ & $\begin{array}{l}\text { Case } \\
\text { series }\end{array}$ & 4 \\
\hline
\end{tabular}

these important items are needed to identify the possible detrimental factors of the laparoscopic approach.

Direct costs after laparoscopic surgery of the rectum are similar or slightly higher than after open surgery. (85.7\% [Consensus])

The scarce data from different studies show uniformly that costs of the laparoscopic approach are higher than after open surgery [130-134]. Arteaga [135] showed an increase in OR costs that balanced with a shorter hospital stay to make total hospital costs similar. All health economy analyses must be used with care, as differences in national health systems and reimbursement systems differ widely. In many systems the direct costs in OR can rarely be compensated in another budget.

Special and new surgical techniques

\section{TEM and transanal local excision}

Patients with T1 cancer and favourable histological features may undergo local excision alone. (85.7\% [Consensus]; GoR B: $78.6 \%$ [Consensus])

When local excision is indicated, transanal endoscopic microsurgery (TEM) is the preferred technique. (92.9\% [Consensus]; GoR B: 79.6\% [Consensus])

Patient selection is the most important factor in successful local excision; however, specific criteria for selecting patients have not been universally accepted. Local treatment of rectal cancer aims to decrease the morbidity and the functional sequelae associated with radical surgery without compromising local tumour control and long-term survival.

Patients with localised superficial tumour (uT1, uN0) may undergo local excision alone. Other additional criteria are tumour size less than $4 \mathrm{~cm}$ and well- or moderately well-differentiated histology. The probability of lymph node metastases for a T1 G1 (well-differentiated) tumour is around $0 \%$ compared with more than $10 \%$ for a T1 G3 (poorly differentiated) tumour [136].

Full-thickness excision of the tumour with lateral margin of $1 \mathrm{~cm}$ and clear margin to the perirectal tissue without tumour fragmentation is essential. This approach allows accurate assessment of histopathological parameters such as margin, differentiation, vascular involvement and depth of penetration [137, 138].

When a local excision is indicated, the minimally invasive endoscopic technique transanal endoscopic microsurgery (TEM) is the preferred technique. Gerhard Bueß originally developed TEM in the 1980s [139, 140]. Conventional transanal excision is mostly limited to low rectal lesions, whereas TEM is preferably used for lesions in the middle and upper third of the rectum that are inaccessible by conventional transanal excision. TEM has been proved to be safe and effective in several case series 
$[141,142]$. Although the evidence regarding TEM is limited, it does appear to result in fewer recurrences compared with conventional transanal excision [143, 144].

\section{NOTES and single port}

No recommendations were established at the consensus conference considering natural orifice transluminal endoscopic surgery (NOTES) and single-incision laparoscopic surgery (SILS). No available data with regard to SILS and NOTES on rectal cancer exist. (100\% [Strong consensus])

According to the EAES recommendations on methodology of innovation management in endoscopic surgery, feasibility and preclinical safety must be established before innovations such as NOTES and SILS become subject of clinical research [145].

Within the last years, significant research efforts have focussed on developing safe and reproducible transluminal endoscopic approaches to perform various intra-abdominal procedures [146]. Recently a first clinical case of NOTES transanal resection for rectal cancer using TEM and laparoscopic assistance has been reported [147]. Improvements in NOTES instrumentation and careful patient selection may allow further clinical application within controlled clinical trials to evaluate safety and outcome of this approach.

\section{Conclusions}

Laparoscopic surgery for middle and low rectal cancer can be recommended under optimal conditions (expert surgeons, expert centres, selected patients, excluding T4). (85.7\% [Consensus]; GoR B: 85.7\% [Consensus])

The vast majority of the panel would recommend the laparoscopic approach for rectal cancer surgery. Still, upcoming results from large randomised trials are awaited to strengthen the evidence for improved short-term results and equal long-term results in comparison with open surgery.

After the recommendations above were presented, data from two randomised controlled trials have been published $[148,149]$. These results strengthen our recommendations by confirming the safety of the laparoscopic approach and providing evidence for no difference in long-term outcome.

In July 2010, Kang et al. published the short-term outcomes of the comparison of open versus laparoscopic surgery for mid and low rectal cancer after neoadjuvant chemoradiotherapy (COREAN) trial, a randomised controlled, multicentre study. Analysis of the criteria associated with long-term oncological outcome such as quality of TME, CRM positivity and number of lymph nodes showed very good results similar to open surgery (incomplete TME in $4.7 \%$ of laparoscopic cases versus $6.5 \%$ in open surgery, positive CRM of $2.9 \%$ in the laparoscopic group versus $4.1 \%$ in the open group, and median 17 lymph nodes versus 18). Furthermore, the authors report a very low conversion rate of $1.2 \%$ and confirmed the known recovery benefits of the laparoscopic approach such as fewer wound complications, less pain and better recovery of intestinal function. These results show that excellent outcomes can be achieved by the laparoscopic approach in expert hands [148].

The 5-year analyses of the Medical Research Council CLASICC trial of laparoscopically assisted versus open surgery for colorectal cancer were published online in July 2010. There was no difference in OS or DFS for patients with rectal cancer with respect to the randomised procedure. For rectal cancer, the 5-year OS rate was $52.9 \%$ for open versus $60.3 \%$ for laparoscopic surgery; the 5-year DFS rate was $52.1 \%$ for open versus $53.2 \%$ for laparoscopic surgery. In patients undergoing anterior resection, the previously reported differences in CRM positivity rates did not translate into a difference in the 5-year local recurrence rate: $7.6 \%$ for open versus $9.4 \%$ for laparoscopic surgery $(p=0.740)$ [149].

Recently, the COLOR II trial comparing laparoscopic and open rectal cancer surgery within a multicentre and multinational setting completed inclusion of more than 1,100 patients. When the panel members demonstrated the first consensus on these recommendations at the 18th International Congress of the EAES in Geneva, Jaap Bonjer presented the first data of the COLOR II trial after recruitment was closed some days before. As of May 2010, 1,103 patients with rectal cancer have been randomised in 30 sites in 8 countries. Valid short-term results from this trial should be released soon, whereas long-term results may be available in some years only $[97,150]$.

Acknowledgements The supportive work of Melanie Rezvani, Christoph Mosch and Tim Mathes, Institute for Research in Operative Medicine (IFOM, Witten/Herdecke University) is highly appreciated.

Disclosures Authors R.S., M.A.C., E.T., F.G.B., M.M., R.C., L.P., E.H., K.B. H.P.B., M.M.H., M.E., and E.A.M.N. have no conflicts of interest or financial ties to disclose. Author A.M.L. is a consultant for Covidien and for Olympus Medical.

\section{References}

1. GLOBOCAN IARC 2008: country fast stat [Internet]. http:// globocan.iarc.fr/factsheets/populations/ factsheet.asp?uno=900\#BOTH. Cited 1 Mar 2011

2. Micheli A (2002) Cancer prevalence in European registry areas. Ann Oncol 13(6):840-865

3. The Clinical Outcomes of Surgical Therapy Study Group (2004) A comparison of laparoscopically assisted and open colectomy for colon cancer. N Engl J Med 350(20):2050-2059 
4. Kuhry E, Schwenk WF, Gaupset R, Romild U, Bonjer HJ (2008) Long-term results of laparoscopic colorectal cancer resection. Cochrane Database Syst Rev (Online) (2):CD003432

5. Buunen M, Veldkamp R, Hop WCJ, Kuhry E, Jeekel J, Haglind E, Påhlman L, Cuesta MA, Msika S, Morino M, Lacy A, Bonjer HJ (2009) Survival after laparoscopic surgery versus open surgery for colon cancer: long-term outcome of a randomised clinical trial. Lancet Oncol 10(1):44-52

6. Levels of Evidence [Internet] (2011). http://www.cebm.net/ index.aspx?o=1025. Cited 1 Mar 2011

7. Council of Europe (2002) Developing a methodology for drawing up guidelines on best medical practice. Council of Europe Publishing, Strasbourg, pp 46-47. ISBN 92-871-4788-4

8. Murphy MK, Black NA, Lamping DL, McKee CM, Sanderson CFB, Askham J, Marteau T (1998) Consensus development methods, and their use in clinical guideline development. Health Technol Assess 2(3):i-iv, 1-88

9. Nicholls RJ, Masona Y, Morson BC, Dixona K, Fry IK (1982) The clinical staging of rectal cancer. Br J Surg 69(7):404-409

10. Schoellhammer HF, Gregorian AC, Sarkisyan GG, Petrie BA (2008) How important is rigid proctosigmoidoscopy in localizing rectal cancer? Am J Surg 196(6):904-908 (discussion 908)

11. Adam IJ, Mohamdee MO, Martin IG, Scott N, Finan PJ, Johnston D, Dixon MF, Quirke P (1994) Role of circumferential margin involvement in the local recurrence of rectal cancer. Lancet 344(8924):707-711

12. Lahaye MJ, Engelen SME, Nelemans PJ, Beets GL, van de Velde CJH, van Engelshoven JMA, Beets-Tan RGH (2005) Imaging for predicting the risk factors-the circumferential resection margin and nodal disease-of local recurrence in rectal cancer: a meta-analysis. Semin Ultrasound CT MR 26(4):259-268

13. Bipat S, Glas AS, Slors FJM, Zwinderman AH, Bossuyt PMM, Stoker J (2004) Rectal cancer: local staging and assessment of lymph node involvement with endoluminal US, CT, and MR imaging — a meta-analysis. Radiology 232(3):773-783

14. Brown G, Radcliffe AG, Newcombe RG, Dallimore NS, Bourne MW, Williams GT (2003) Preoperative assessment of prognostic factors in rectal cancer using high-resolution magnetic resonance imaging. Br J Surg 90(3):355-364

15. MERCURY Study Group (2006) Diagnostic accuracy of preoperative magnetic resonance imaging in predicting curative resection of rectal cancer: prospective observational study. BMJ (Clinical Res Ed) 333(7572):779

16. Mathur P, Smith JJ, Ramsey C, Owen M, Thorpe A, Karim S, Burke C, Ramesh S, Dawson PM (2003) Comparison of CT and MRI in the pre-operative staging of rectal adenocarcinoma and prediction of circumferential resection margin involvement by MRI. Colorectal Dis 5(5):396-401

17. Mauchley DC, Lynge DC, Langdale LA, Stelzner MG, Mock CN, Billingsley KG (2005) Clinical utility and cost-effectiveness of routine preoperative computed tomography scanning in patients with colon cancer. Am J Surg 189(5):512-517 (discussion 517)

18. Barillari P, Ramacciato G, De Angelis R, Gozzo P, Indinnimeo M, Valabrega S, Aurello P, Fegiz G (1990) Effect of preoperative colonoscopy on the incidence of synchronous and metachronous neoplasms. Acta Chirurg Scand 156(2):163-166

19. Chen HS, Sheen-Chen SM (2000) Synchronous and "early" metachronous colorectal adenocarcinoma: analysis of prognosis and current trends. Dis Colon Rectum 43(8):1093-1099

20. Copel L, Sosna J, Kruskal JB, Raptopoulos V, Farrell RJ, Morrin MM (2007) CT colonography in 546 patients with incomplete colonoscopy. Radiology 244(2):471-478

21. Coccetta M, Migliaccio C, La Mura F, Farinella E, Galanou I, Delmonaco P, Spizzirri A, Napolitano V, Cattorini L, Milani D,
Cirocchi R, Sciannameo F (2009) Virtual colonoscopy in stenosing colorectal cancer. Ann Surg Innov Res 3:11

22. Duffy MJ, van Dalen A, Haglund C, Hansson L, Holinski-Feder E, Klapdor R, Lamerz R, Peltomaki P, Sturgeon C, Topolcan O (2007) Tumour markers in colorectal cancer: European Group on Tumour Markers (EGTM) guidelines for clinical use. Eur J Cancer 43(9): 1348-1360

23. Locker GY, Hamilton S, Harris J, Jessup JM, Kemeny N, Macdonald JS, Somerfield MR, Hayes DF, Bast RC (2006) ASCO 2006 update of recommendations for the use of tumor markers in gastrointestinal cancer. J Clin Oncol 24(33):5313-5327

24. Park YJ, Youk EG, Choi HS, Han SU, Park KJ, Lee KU, Choe KJ, Park JG (1999) Experience of 1446 rectal cancer patients in Korea and analysis of prognostic factors. Int J Colorectal Dis 14(2):101-106

25. Park YJ, Park KJ, Park JG, Lee KU, Choe KJ, Kim JP (1999) Prognostic factors in 2230 Korean colorectal cancer patients: analysis of consecutively operated cases. World J Surg 23(7): 721-726

26. Valentini V, Aristei C, Glimelius B, Minsky BD, Beets-Tan R, Borras JM, Haustermans K, Maingon P, Overgaard J, Pahlman L, Quirke P, Schmoll H-J, Sebag-Montefiore D, Taylor I, Van Cutsem E, Van de Velde C, Cellini N, Latini P (2009) Multidisciplinary Rectal Cancer Management: 2nd European Rectal Cancer Consensus Conference (EURECA-CC2). Radiat Oncol 92(2): $148-163$

27. (1997) Improved survival with preoperative radiotherapy in resectable rectal cancer. Swedish Rectal Cancer Trial. N Engl J Med 336(14):980-987

28. Kapiteijn E, Marijnen CA, Nagtegaal ID, Putter H, Steup WH, Wiggers T, Rutten HJ, Pahlman L, Glimelius B, Krieken JH, van Leer JW, van de Velde CJ (2001) Preoperative radiotherapy combined with total mesorectal excision for resectable rectal cancer. N Engl J Med 345(9):638-646

29. Cammà C, Giunta M, Fiorica F, Pagliaro L, Craxì A, Cottone M (2000) Preoperative radiotherapy for resectable rectal cancer: A meta-analysis. JAMA 284(8):1008-1015

30. Folkesson J, Birgisson H, Pahlman L, Cedermark B, Glimelius B, Gunnarsson U (2005) Swedish Rectal Cancer Trial: long lasting benefits from radiotherapy on survival and local recurrence rate. J Clin Oncol 23(24):5644-5650

31. Heald RJ, Moran BJ, Ryall RD, Sexton R, MacFarlane JK (1998) Rectal cancer: the Basingstoke experience of total mesorectal excision, 1978-1997. Arch Surg 133(8):894-899

32. Peeters KCMJ, Marijnen CAM, Nagtegaal ID, Kranenbarg EK, Putter H, Wiggers T, Rutten H, Pahlman L, Glimelius B, Leer JW, van de Velde CJH (2007) The TME trial after a median follow-up of 6 years: increased local control but no survival benefit in irradiated patients with resectable rectal carcinoma. Ann Surg 246(5):693-701

33. Sebag-Montefiore D, Stephens RJ, Steele R, Monson J, Grieve R, Khanna S, Quirke P, Couture J, de Metz C, Myint AS (2009) Preoperative radiotherapy versus selective postoperative chemoradiotherapy in patients with rectal cancer (MRC CR07 and NCIC-CTG C016): a multicentre, randomised trial. Lancet 373(9666):811-820

34. Frykholm GJ, Glimelius B, Påhlman L (1993) Preoperative or postoperative irradiation in adenocarcinoma of the rectum: final treatment results of a randomized trial and an evaluation of late secondary effects. Dis Colon Rectum 36(6):564-572

35. Sauer R, Becker H, Hohenberger W, Rödel C, Wittekind C, Fietkau R, Martus P, Tschmelitsch J, Hager E, Hess CF, Karstens J-H, Liersch T, Schmidberger H, Raab R (2004) Preoperative versus postoperative chemoradiotherapy for rectal cancer. N Engl J Med 351(17):1731-1740 
36. Bujko K, Nowacki MP, Nasierowska-Guttmejer A, Michalski W, Bebenek M, Kryj M (2006) Long-term results of a randomized trial comparing preoperative short-course radiotherapy with preoperative conventionally fractionated chemoradiation for rectal cancer. Br J Surg 93(10):1215-1223

37. McLachlan S, Fisher R, McClure B, Beresford J, McKendrick J, Mackay J, Solomon M, Burmeister B, Hartopeanu C, Ngan S (2008) A comparison of quality of life in patients with T3 rectal cancer receiving short course versus long course preoperative radiation. A Trans-Tasman Radiation Oncology Group Trial (TROG 01.04). J Clin Oncol (Meeting Abstracts) 26(15202s)

38. Siegel R, Burock S, Wernecke K-D, Kretzschmar A, Dietel M, Loy V, Koswig S, Budach V, Schlag PM (2009) Preoperative short-course radiotherapy versus combined radiochemotherapy in locally advanced rectal cancer: a multi-centre prospectively randomised study of the Berlin Cancer Society. BMC Cancer 9:50

39. O'Connell MJ, Martenson JA, Wieand HS, Krook JE, Macdonald JS, Haller DG, Mayer RJ, Gunderson LL, Rich TA (1994) Improving adjuvant therapy for rectal cancer by combining protracted-infusion fluorouracil with radiation therapy after curative surgery. N Engl J Med 331(8):502-507

40. Meta-analysis Group in Cancer (1998) Efficacy of intravenous continuous infusion of fluorouracil compared with bolus administration in advanced colorectal cancer. J Clin Oncol 16(1):301-308

41. Kim JS, Kim JS, Cho MJ, Yoon WH, Song KS (2006) Comparison of the efficacy of oral capecitabine versus bolus 5-FU in preoperative radiotherapy of locally advanced rectal cancer. J Korean Med Sci 21(1):52-57

42. Marijnen CAM, Leer JWH, Putter H, Kapiteijn E, van Krieken JHJM, Noordijk EM, van de Velde CJH (2001) Interval between preoperative radiotherapy and surgery influences postoperative mortality in rectal cancer patients: the sooner the better. Eur J Cancer 37(Suppl 6):S273

43. Pettersson D, Cedermark B, Holm T, Radu C, Påhlman L, Glimelius B, Martling A (2010) Interim analysis of the Stockholm III trial of preoperative radiotherapy regimens for rectal cancer. Br J Surg 97(4):580-587

44. Neugebauer EAM, Sauerland S, Fingerhut A (2006) EAES guidelines for endoscopic surgery: twelve years evidence-based surgery in Europe. Springer, Berlin

45. Guenaga KKFG, Matos D, Wille-Jørgensen P (2009) Mechanical bowel preparation for elective colorectal surgery. Cochrane Database Syst Rev (Online) (1):CD001544

46. Slim K, Vicaut E, Launay-Savary M-V, Contant C, Chipponi J (2009) Updated systematic review and meta-analysis of randomized clinical trials on the role of mechanical bowel preparation before colorectal surgery. Ann Surg 249(2):203-209

47. Zhu QD, Zhang QY, Zeng QQ, Yu ZP, Tao CL, Yang WJ (2010) Efficacy of mechanical bowel preparation with polyethylene glycol in prevention of postoperative complications in elective colorectal surgery: a meta-analysis. Int J Colorectal Dis 25(2):267-275

48. Ulrich AB, Seiler C, Rahbari N, Weitz J, Büchler MW (2009) Diverting stoma after low anterior resection: more arguments in favor. Dis Colon Rectum 52(3):412-418

49. Matthiessen P, Hallböök O, Rutegård J, Simert G, Sjödahl R (2007) Defunctioning stoma reduces symptomatic anastomotic leakage after low anterior resection of the rectum for cancer: a randomized multicenter trial. Ann Surg 246(2):207-214

50. Van't Sant HP, Weidema WF, Hop WCJ, Oostvogel HJM, Contant CME (2010) The influence of mechanical bowel preparation in elective lower colorectal surgery. Ann Surg 251(1):59-63

51. Bretagnol F, Alves A, Ricci A, Valleur P, Panis Y (2007) Rectal cancer surgery without mechanical bowel preparation. Br J Surg 94(10):1266-1271
52. Schwenk W (2009) [Fast track rehabilitation in visceral surgery]. Der Chirurg; Zeitschrift für alle Gebiete der operativen Medizen 80(8):690-701

53. Levy BF, Tilney HS, Dowson HMP, Rockall TA (2010) A systematic review of postoperative analgesia following laparoscopic colorectal surgery. Colorectal Dis 12(1):5-15

54. McCarthy GC, Megalla SA, Habib AS (2010) Impact of intravenous lidocaine infusion on postoperative analgesia and recovery from surgery: a systematic review of randomized controlled trials. Drugs 70(9):1149-1163

55. White PF, Kehlet H (2010) Improving postoperative pain management: what are the unresolved issues? Anesthesiology 112(1):220-225

56. Brandstrup B, Tønnesen H, Beier-Holgersen R, Hjorts $\emptyset$ E, Ørding H, Lindorff-Larsen K, Rasmussen MS, Lanng C, Wallin L, Iversen LH, Gramkow CS, Okholm M, Blemmer T, Svendsen P-E, Rottensten HH, Thage B, Riis J, Jeppesen IS, Teilum D, Christensen AM, Graungaard B, Pott F (2003) Effects of intravenous fluid restriction on postoperative complications: comparison of two perioperative fluid regimens: a randomized assessor-blinded multicenter trial. Ann Surg 238(5):641-648

57. Holte K, Kehlet H (2006) Fluid therapy and surgical outcomes in elective surgery: a need for reassessment in fast-track surgery. J Am Coll Surg 202(6):971-989

58. Lobo DN, Bostock KA, Neal KR, Perkins AC, Rowlands BJ, Allison SP (2002) Effect of salt and water balance on recovery of gastrointestinal function after elective colonic resection: a randomised controlled trial. Lancet 359(9320):1812-1818

59. Nisanevich V, Felsenstein I, Almogy G, Weissman C, Einav S, Matot I (2005) Effect of intraoperative fluid management on outcome after intraabdominal surgery. Anesthesiology 103(1): 25-32

60. Rahbari NN, Zimmermann JB, Schmidt T, Koch M, Weigand MA, Weitz J (2009) Meta-analysis of standard, restrictive and supplemental fluid administration in colorectal surgery. Br J Surg 96(4):331-341

61. Nelson RL, Glenny AM, Song F (2009) Antimicrobial prophylaxis for colorectal surgery. Cochrane Database Syst Rev (Online) (1):CD001181

62. Lassen K, Kjaeve J, Fetveit T, Tranø G, Sigurdsson HK, Horn A, Revhaug A (2008) Allowing normal food at will after major upper gastrointestinal surgery does not increase morbidity: a randomized multicenter trial. Ann Surg 247(5):721-729

63. Lewis SJ, Egger M, Sylvester PA, Thomas S (2001) Early enteral feeding versus "nil by mouth" after gastrointestinal surgery: systematic review and meta-analysis of controlled trials. BMJ (Clin Res Ed) 323(7316):773-776

64. Lassen K, Soop M, Nygren J, Cox PBW, Hendry PO, Spies C, von Meyenfeldt MF, Fearon $\mathrm{KCH}$, Revhaug A, Norderval S, Ljungqvist O, Lobo DN, Dejong CHC (2009) Consensus review of optimal perioperative care in colorectal surgery: Enhanced Recovery After Surgery (ERAS) Group recommendations. Arch Surg 144(10):961-969

65. Baan AH, Vermeulen H, van der Meulen J, Bossuyt P, Olszyna D, Gouma DJ (2003) The effect of suprapubic catheterization versus transurethral catheterization after abdominal surgery on urinary tract infection: a randomized controlled trial. Dig Surg 20(4):290-295

66. Targarona EM, Balague C, Marin J, Neto RB, Martinez C, Garriga J, Trias M (2005) Energy sources for laparoscopic colectomy: a prospective randomized comparison of conventional electrosurgery, bipolar computer-controlled electrosurgery and ultrasonic dissection. Operative outcome and costs analysis. Surg Innov 12(4):339-344

67. Harold KL, Pollinger H, Matthews BD, Kercher KW, Sing RF, Heniford BT (2003) Comparison of ultrasonic energy, bipolar 
thermal energy, and vascular clips for the hemostasis of small-, medium-, and large-sized arteries. Surg Endosc 17(8):1228-1230

68. Hübner M, Hahnloser D, Hetzer F, Müller MK, Clavien P-A, Demartines N (2007) A prospective randomized comparison of two instruments for dissection and vessel sealing in laparoscopic colorectal surgery. Surg Endosc 21(4):592-594

69. Campagnacci R, de Sanctis A, Baldarelli M, Rimini M, Lezoche G, Guerrieri M (2007) Electrothermal bipolar vessel sealing device vs. ultrasonic coagulating shears in laparoscopic colectomies: a comparative study. Surg Endosc 21(9):1526-1531

70. Morino M, Rimonda R, Allaix ME, Giraudo G, Garrone C (2005) Ultrasonic versus standard electric dissection in laparoscopic colorectal surgery: a prospective randomized clinical trial. Ann Surg 242(6):897-901 (discussion 901)

71. Zhou B-J, Song W-Q, Yan Q-H, Cai J-H, Wang F-A, Liu J, Zhang G-J, Duan G-Q, Zhang Z-X (2008) Ultrasonically activated scalpel versus monopolar electrocautery shovel in laparoscopic total mesorectal excision for rectal cancer. World $\mathrm{J}$ Gastroenterol 14(25):4065-4069

72. Heald RJ (1995) Total mesorectal excision is optimal surgery for rectal cancer: a Scandinavian consensus. Br J Surg 82(10): 1297-1299

73. Nagtegaal ID, van de Velde CJH, van der Worp E, Kapiteijn E, Quirke P, van Krieken JHJM (2002) Macroscopic evaluation of rectal cancer resection specimen: clinical significance of the pathologist in quality control. J Clin Oncol 20(7):1729-1734

74. Rullier E, Laurent C, Bretagnol F, Rullier A, Vendrely V, Zerbib F (2005) Sphincter-saving resection for all rectal carcinomas: the end of the 2-cm distal rule. Ann Surg 241(3):465-469

75. Poulin EC, Mamazza J, Schlachta CM, Grégoire R, Roy N (1999) Laparoscopic resection does not adversely affect early survival curves in patients undergoing surgery for colorectal adenocarcinoma. Ann Surg 229(4):487-492

76. Leung KL, Kwok SP, Lau WY, Meng WC, Lam TY, Kwong KH, Chung CC, Li AK (1997) Laparoscopic-assisted resection of rectosigmoid carcinoma, Immediate and medium-term results. Arch Surg 132(7):761-764 (discussion 765)

77. Bärlehner E, Decker T, Anders S, Heukrodt B (2001) Laparoscopic surgery of rectal carcinoma. Radical oncology and late results. Z Chirurgie 126(4):302-306

78. Morino M, Parini U, Giraudo G, Salval M, Brachet Contul R, Garrone C (2003) Laparoscopic total mesorectal excision: a consecutive series of 100 patients. Ann Surg 237(3):335-342

79. Delgado S, Momblán D, Salvador L, Bravo R, Castells A, Ibarzabal A, Piqué JM, Lacy AM (2004) Laparoscopic-assisted approach in rectal cancer patients: lessons learned from $>200$ patients. Surg Endosc 18(10):1457-1462

80. Leroy J, Jamali F, Forbes L, Smith M, Rubino F, Mutter D, Marescaux J (2004) Laparoscopic total mesorectal excision (TME) for rectal cancer surgery: long-term outcomes. Surg Endosc 18(2):281-289

81. Zhou Z-G, Hu M, Li Y, Lei W-Z, Yu Y-Y, Cheng Z, Li L, Shu Y, Wang T-C (2004) Laparoscopic versus open total mesorectal excision with anal sphincter preservation for low rectal cancer. Surg Endosc 18(8):1211-1215

82. Dulucq J-L, Wintringer P, Stabilini C, Mahajna A (2005) Laparoscopic rectal resection with anal sphincter preservation for rectal cancer: long-term outcome. Surg Endosc 19(11):1468-1474

83. Bretagnol F, Lelong B, Laurent C, Moutardier V, Rullier A, Monges G, Delpero J-R, Rullier E (2005) The oncological safety of laparoscopic total mesorectal excision with sphincter preservation for rectal carcinoma. Surg Endosc 19(7):892-896

84. Morino M, Allaix ME, Giraudo G, Corno F, Garrone C (2005) Laparoscopic versus open surgery for extraperitoneal rectal cancer: a prospective comparative study. Surg Endosc 19(11): $1460-1467$
85. Veenhof AAFA, Engel AF, Craanen ME, Meijer S, de Lange-de Klerk ESM, van der Peet DL, Meijerink WJHJ, Cuesta MA (2007) Laparoscopic versus open total mesorectal excision: a comparative study on short-term outcomes. A single-institution experience regarding anterior resections and abdominoperineal resections. Dig Surg 24(5):367-374

86. Martinez C, Targarona EM, Balague C (2007) Laparoscopic surgery for treatmetn of rectal cancer. A single center 8 year experience. Surg Endosc 21:S190

87. Laurent C, Leblanc F, Gineste C, Saric J, Rullier E (2007) Laparoscopic approach in surgical treatment of rectal cancer. $\mathrm{Br}$ J Surg 94(12):1555-1561

88. Lujan J, Valero G, Hernandez Q, Sanchez A, Frutos MD, Parrilla P (2009) Randomized clinical trial comparing laparoscopic and open surgery in patients with rectal cancer. Br J Surg 96(9): 982-989

89. Kuroyanagi H, Akiyoshi T, Oya M, Fujimoto Y, Ueno M, Yamaguchi T, Muto T (2009) Laparoscopic-assisted anterior resection with double-stapling technique anastomosis: safe and feasible for lower rectal cancer? Surg Endosc 23(10):2197-2202

90. Ito M, Sugito M, Kobayashi A, Nishizawa Y, Tsunoda Y, Saito N (2008) Relationship between multiple numbers of stapler firings during rectal division and anastomotic leakage after laparoscopic rectal resection. Int J Colorectal Dis 23(7):703-707

91. Peeters KCMJ, Tollenaar RAEM, Marijnen CAM, Klein Kranenbarg E, Steup WH, Wiggers T, Rutten HJ, van de Velde CJH (2005) Risk factors for anastomotic failure after total mesorectal excision of rectal cancer. Br J Surg 92(2):211-216

92. Hüser N, Michalski CW, Erkan M, Schuster T, Rosenberg R, Kleeff J, Friess H (2008) Systematic review and meta-analysis of the role of defunctioning stoma in low rectal cancer surgery. Ann Surg 248(1):52-60

93. Veenhof AAFA, Engel AF, van der Peet DL, Sietses C, Meijerink WJHJ, de Lange-de Klerk ESM, Cuesta MA (2008) Technical difficulty grade score for the laparoscopic approach of rectal cancer: a single institution pilot study. Int J Colorectal Dis 23(5):469-475

94. Targarona EM, Balague C, Pernas JC, Martinez C, Berindoague R, Gich I, Trias M (2008) Can we predict immediate outcome after laparoscopic rectal surgery? Multivariate analysis of clinical, anatomic, and pathologic features after 3-dimensional reconstruction of the pelvic anatomy. Ann Surg 247(4):642-649

95. Brannigan AE, De Buck S, Suetens P, Penninckx F, D $\square$ Hoore A (2006) Intracorporeal rectal stapling following laparoscopic total mesorectal excision: overcoming a challenge. Surg Endosc 20(6):952-955

96. Soop M, Nelson H (2008) Laparoscopic-assisted proctectomy for rectal cancer: on trial. Ann Surg Oncol 15(9):2357-2359

97. Buunen M, Bonjer HJ, Hop WCJ, Haglind E, Kurlberg G, Rosenberg J, Lacy AM, Cuesta MA, DH $\square$ oore A, Fürst A, Lange JF, Jess P, Bulut O, Poornoroozy P, Jensen KJ, Christensen MM, Lundhus E, Ovesen H, Birch D, Iesalnieks I, Jäger C, Kreis M, van Riet Y, van der Harst E, Gerhards MF, Bemelman WA, Hansson BME, Neijenhuis PA, Prins HA, Balague C, Targarona E, Luján Mompeán JA, Franco Osorio JD, Garcia Molina FJ, Skullman S, Läckberg Z, Kressner U, Matthiessen P, Kim SH, Poza AA (2009) COLOR II. A randomized clinical trial comparing laparoscopic and open surgery for rectal cancer. Danish Med Bull 56(2):89-91

98. Tjandra JJ, Chan MKY, Yeh CH (2008) Laparoscopic- vs. handassisted ultralow anterior resection: a prospective study. Dis Colon Rectum 51(1):26-31

99. Yamaguchi Y, Minami K, Kawabuchi Y, Emi M, Toge T (2005) Anterior resection of rectal cancer through a one hand-size incision with or without laparoscopy: proposal of one hand-size incision surgery (OHaSIS). J Surg Res 129(1):136-141 
100. Baik SH, Ko YT, Kang CM, Lee WJ, Kim NK, Sohn SK, Chi HS, Cho CH (2008) Robotic tumor-specific mesorectal excision of rectal cancer: short-term outcome of a pilot randomized trial. Surg Endosc 22(7):1601-1608

101. Choi DJ, Kim SH, Lee PJM, Kim J, Woo SU (2009) Singlestage totally robotic dissection for rectal cancer surgery: technique and short-term outcome in 50 consecutive patients. Dis Colon Rectum 52(11):1824-1830

102. Patriti A, Ceccarelli G, Bartoli A, Spaziani A, Biancafarina A, Casciola L (2009) Short- and medium-term outcome of robotassisted and traditional laparoscopic rectal resection. JSLS 13(2): 176-183

103. Civello IM, Cavicchioni C, Tacchino RM, Matera D, Valentini V, Manfrida S, Greco F (2007) Laparoscopic resection with intraoperative radiotherapy: a new step in the multimodal treatment of advanced colorectal cancer. Surg Endosc 21(2):330-332

104. Vithiananthan S, Cooper Z, Betten K, Stapleton GS, Carter J, Huang EH, Whelan RL (2001) Hybrid laparoscopic flexure takedown and open procedure for rectal resection is associated with significantly shorter length of stay than equivalent open resection. Dis Colon Rectum 44(7):927-935

105. Ng K-H, Ng DC-K, Cheung HY-S, Wong JC-H, Yau KK-K, Chung CC-C, Li MK-W (2009) Laparoscopic resection for rectal cancers: lessons learned from 579 cases. Ann Surg 249(1):82-86

106. Bretagnol F, Rullier E, Couderc P, Rullier A, Saric J (2003) Technical and oncological feasibility of laparoscopic total mesorectal excision with pouch coloanal anastomosis for rectal cancer. Colorectal Dis 5(5):451-453

107. Fürst A, Suttner S, Agha A, Beham A, Jauch K-W (2003) Colonic J-pouch vs. coloplasty following resection of distal rectal cancer: early results of a prospective, randomized, pilot study. Dis Colon Rectum 46(9):1161-1166

108. Liang J-T, Lai H-S, Lee P-H, Huang K-C (2007) Comparison of functional and surgical outcomes of laparoscopic-assisted colonic J-pouch versus straight reconstruction after total mesorectal excision for lower rectal cancer. Ann Surg Oncol 14(7):1972-1979

109. Brown CJ, Fenech DS, McLeod RS (2008) Reconstructive techniques after rectal resection for rectal cancer. Cochrane Database Syst Rev (Online) (2):CD006040

110. Fazio VW, Zutshi M, Remzi FH, Parc Y, Ruppert R, Fürst A, Celebrezze J, Galanduik S, Orangio G, Hyman N, Bokey L, Tiret E, Kirchdorfer B, Medich D, Tietze M, Hull T, Hammel J (2007) A randomized multicenter trial to compare long-term functional outcome, quality of life, and complications of surgical procedures for low rectal cancers. Ann Surg 246(3):481-488 (discussion 488-490)

111. Rullier E, Sa Cunha A, Couderc P, Rullier A, Gontier R, Saric J (2003) Laparoscopic intersphincteric resection with coloplasty and coloanal anastomosis for mid and low rectal cancer. Br J Surg 90(4):445-451

112. Pugliese R, Di Lernia S, Sansonna F, Scandroglio I, Maggioni D, Ferrari GC, Costanzi A, Magistro C, De Carli S (2008) Results of laparoscopic anterior resection for rectal adenocarcinoma: retrospective analysis of 157 cases. Am J Surg 195(2): 233-238

113. Targarona EM, Pons MJ, Anglada MT, Taurá P, Trias M (1993) Laparoscopic abdominoperineal resection of the rectum. Br J Surg 80(4):535

114. Larach SW, Salomon MC, Williamson PR, Goldstein E (1993) Laparoscopic assisted abdominoperineal resection. Surg Laparosc Endosc 3(2):115-118

115. Darzi A, Lewis C, Menzies-Gow N, Guillou PJ, Monson JR (1995) Laparoscopic abdominoperineal excision of the rectum. Surg Endosc 9(4):414-417
116. Scheidbach H, Schneider C, Konradt J, Bärlehner E, Köhler L, Wittekind C, Köckerling F (2002) Laparoscopic abdominoperineal resection and anterior resection with curative intent for carcinoma of the rectum. Surg Endosc 16(1):7-13

117. Baker RP, White EE, Titu L, Duthie GS, Lee PWR, Monson JRT (2002) Does laparoscopic abdominoperineal resection of the rectum compromise long-term survival? Dis Colon Rectum 45(11):1481-1485

118. Guillou PJ, Quirke P, Thorpe H, Walker J, Jayne DG, Smith AMH, Heath RM, Brown JM (2005) Short-term endpoints of conventional versus laparoscopic-assisted surgery in patients with colorectal cancer (MRC CLASICC trial): multicentre, randomised controlled trial. Lancet 365(9472):1718-1726

119. Koerner K, Datena S, Erwin L (1997) Laparoscopic-assisted abdominoperineal resection in the prone position. An alternative technique. Surg Endosc 11(6):684-686

120. West NP, Anderin C, Smith KJE, Holm T, Quirke P (2010) Multicentre experience with extralevator abdominoperineal excision for low rectal cancer. Br J Surg 97(4):588-599

121. Holm T, Ljung A, Häggmark T, Jurell G, Lagergren J (2007) Extended abdominoperineal resection with gluteus maximus flap reconstruction of the pelvic floor for rectal cancer. Br J Surg 94(2):232-238

122. Biondo S, Ortiz H, Lujan J, Codina-Cazador A, Espin E, GarciaGranero E, Kreisler E, de Miguel M, Alos R, Echeverria A (2010) Quality of mesorectum after laparoscopic resection for rectal cancer-results of an audited teaching programme in Spain. Colorectal Dis 12(1):24-31

123. Laurent C, Leblanc F, Wütrich P, Scheffler M, Rullier E (2009) Laparoscopic versus open surgery for rectal cancer: long-term oncologic results. Ann Surg 250(1):54-61

124. Breukink S, Pierie J, Wiggers T (2006) Laparoscopic versus open total mesorectal excision for rectal cancer. Cochrane Database Syst Rev (Online) (4):CD005200

125. Varela JE, Wilson SE, Nguyen NT (2010) Laparoscopic surgery significantly reduces surgical-site infections compared with open surgery. Surg Endosc 24(2):270-276

126. Dobson MW, Geisler D, Fazio V, Remzi F, Hull T, Vogel J (2011) Minimally invasive surgical wound infections: laparoscopic surgery decreases morbidity of surgical site infections and decreases the cost of wound care. Colorectal Dis 13(7): $811-815$

127. Gujral S, Avery KNL, Blazeby JM (2008) Quality of life after surgery for colorectal cancer: clinical implications of results from randomised trials. Support Care Cancer 16(2):127-132

128. Fujii S, Ota M, Ichikawa Y, Yamagishi S, Watanabe K, Tatsumi K, Watanabe J, Suwa H, Oshima T, Kunisaki C, Ohki S, Endo I, Shimada H (2010) Comparison of short, long-term surgical outcomes and mid-term health-related quality of life after laparoscopic and open resection for colorectal cancer: a case-matched control study. Int J Colorectal Dis 25(11):1311-1323

129. Scarpa M, Erroi F, Ruffolo C, Mollica E, Polese L, Pozza G, Norberto L, D'Amico DF, Angriman I (2009) Minimally invasive surgery for colorectal cancer: quality of life, body image, cosmesis, and functional results. Surg Endosc 23(3):577-582

130. Park J-S, Kang S-B, Kim S-W, Cheon G-N (2007) Economics and the laparoscopic surgery learning curve: comparison with open surgery for rectosigmoid cancer. World J Surg 31(9): $1827-1834$

131. Franks PJ, Bosanquet N, Thorpe H, Brown JM, Copeland J, Smith AMH, Quirke P, Guillou PJ (2006) Short-term costs of conventional vs laparoscopic assisted surgery in patients with colorectal cancer (MRC CLASICC trial). Br J Cancer 95(1): 6-12

132. Braga M, Frasson M, Vignali A, Zuliani W, Capretti G, Di Carlo V (2007) Laparoscopic resection in rectal cancer patients: 
outcome and cost-benefit analysis. Dis Colon Rectum 50(4): 464-471

133. Dowson HM, Huang A, Soon Y, Gage H, Lovell DP, Rockall TA (2007) Systematic review of the costs of laparoscopic colorectal surgery. Dis Colon Rectum 50(6):908-919

134. De Verteuil RM, Hernández RA, Vale L (2007) Economic evaluation of laparoscopic surgery for colorectal cancer. Int $\mathrm{J}$ Technol Assess Health Care 23(4):464-472

135. Arteaga González I, Díaz Luis H, Martín Malagón A, LópezTomassetti Fernández EM, Arranz Duran J, Carrillo Pallares A (2006) A comparative clinical study of short-term results of laparoscopic surgery for rectal cancer during the learning curve. Int J Colorectal Dis 21(6):590-595

136. Sengupta S, Tjandra JJ (2001) Local excision of rectal cancer: what is the evidence? Dis Colon Rectum 44(9):1345-1361

137. Nastro P, Beral D, Hartley J, Monson JR (2005) Local excision of rectal cancer: review of literature. Dig Surg 22(1-2):6-15

138. Perretta S (2006) Surgical treatment of rectal cancer: local resection. Surg Oncol Clin N Am 15(1):67-93

139. Buess G, Hutterer F, Theiss J, Böbel M, Isselhard W, Pichlmaier H (1984) [A system for a transanal endoscopic rectum operation]. Der Chirurg; Z Gebiete der operativen Medizen 55(10): 677-680

140. Buess G, Kipfmüller K, Hack D, Grüssner R, Heintz A, Junginger $\mathrm{T}$ (1988) Technique of transanal endoscopic microsurgery. Surg Endosc 2(2):71-75

141. Bretagnol F, Merrie A, George B, Warren BF, Mortensen NJ (2007) Local excision of rectal tumours by transanal endoscopic microsurgery. Br J Surg 94(5):627-633

142. Ganai S, Kanumuri P, Rao RS, Alexander AI (2006) Local recurrence after transanal endoscopic microsurgery for rectal polyps and early cancers. Ann Surg Oncol 13(4):547-556

143. Middleton PF, Sutherland LM, Maddern GJ (2005) Transanal endoscopic microsurgery: a systematic review. Dis Colon Rectum 48(2):270-284

144. Christoforidis D, Cho H-M, Dixon MR, Mellgren AF, Madoff RD, Finne CO (2009) Transanal endoscopic microsurgery versus conventional transanal excision for patients with early rectal cancer. Ann Surg 249(5):776-782

145. Neugebauer EAM, Becker M, Buess GF, Cuschieri A, Dauben H-P, Fingerhut A, Fuchs KH, Habermalz B, Lantsberg L, Morino M, Reiter-Theil S, Soskuty G, Wayand W, Welsch T (2010) EAES recommendations on methodology of innovation management in endoscopic surgery. Surg Endosc 24(7):1594-1615

146. Flora ED, Wilson TG, Martin IJ, O'Rourke NA, Maddern GJ (2008) A review of natural orifice translumenal endoscopic surgery (NOTES) for intra-abdominal surgery: experimental models, techniques, and applicability to the clinical setting. Ann Surg 247(4):583-602

147. Sylla P, Rattner DW, Delgado S, Lacy AM (2010) NOTES transanal rectal cancer resection using transanal endoscopic microsurgery and laparoscopic assistance. Surg Endosc 24(5): $1205-1210$
148. Kang S-B, Park JW, Jeong S-Y, Nam BH, Choi HS, Kim D-W, Lim S-B, Lee T-G, Kim DY, Kim J-S, Chang HJ, Lee H-S, Kim SY, Jung KH, Hong YS, Kim JH, Sohn DK, Kim D-H, Oh JH (2010) Open versus laparoscopic surgery for mid or low rectal cancer after neoadjuvant chemoradiotherapy (COREAN trial): short-term outcomes of an open-label randomised controlled trial. Lancet Oncol 11(7):637-645

149. Jayne DG, Thorpe HC, Copeland J, Quirke P, Brown JM, Guillou PJ (2010) Five-year follow-up of the Medical Research Council CLASICC trial of laparoscopically assisted versus open surgery for colorectal cancer. Br J Surg 97(11):1638-1645

150. COLOR II: Laparoscopic Versus Open Rectal Cancer Removal-Full Text View-ClinicalTrials.gov [Internet]. http://clinicaltrials.gov/ct2/show/NCT00297791?term=rectal+ cancer + AND + surgery + AND + COLOR\&rank $=1$. Cited 1 Mar 2011

151. Quah HM, Jayne DG, Eu KW, Seow-Choen F (2002) Bladder and sexual dysfunction following laparoscopically assisted and conventional open mesorectal resection for cancer. Br J Surg 89(12):1551-1556

152. Anthuber M, Fuerst A, Elser F, Berger R, Jauch K-W (2003) Outcome of laparoscopic surgery for rectal cancer in 101 patients. Dis Colon Rectum 46(8):1047-1053

153. Tsang WWC, Chung CC, Kwok SY, Li MKW (2006) Laparoscopic sphincter-preserving total mesorectal excision with colonic J-pouch reconstruction: five-year results. Ann Surg 243(3):353-358

154. Agha A, Fürst A, Hierl J, Iesalnieks I, Glockzin G, Anthuber M, Jauch K-W, Schlitt HJ (2008) Laparoscopic surgery for rectal cancer: oncological results and clinical outcome of 225 patients. Surg Endosc 22(10):2229-2237

155. Jayne DG, Brown JM, Thorpe H, Walker J, Quirke P, Guillou PJ (2005) Bladder and sexual function following resection for rectal cancer in a randomized clinical trial of laparoscopic versus open technique. Br J Surg 92(9):1124-1132

156. Liang J-T, Lai H-S, Lee P-H (2007) Laparoscopic pelvic autonomic nerve-preserving surgery for patients with lower rectal cancer after chemoradiation therapy. Ann Surg Oncol 14(4): $1285-1287$

157. Breukink SO, van Driel MF, Pierie JPEN, Dobbins C, Wiggers T, Meijerink WJHJ (2008) Male sexual function and lower urinary tract symptoms after laparoscopic total mesorectal excision. Int J Colorectal Dis 23(12):1199-1205

158. Asoglu O, Matlim T, Karanlik H, Atar M, Muslumanoglu M, Kapran Y, Igci A, Ozmen V, Kecer M, Parlak M (2009) Impact of laparoscopic surgery on bladder and sexual function after total mesorectal excision for rectal cancer. Surg Endosc 23(2): 296-303

159. Morino M, Parini U, Allaix ME, Monasterolo G, Brachet Contul R, Garrone C (2009) Male sexual and urinary function after laparoscopic total mesorectal excision. Surg Endosc 23(6): $1233-1240$ 